\title{
Nests of red wood ants (Formica rufa-group) are positively associated with tectonic faults: a double-blind test
}

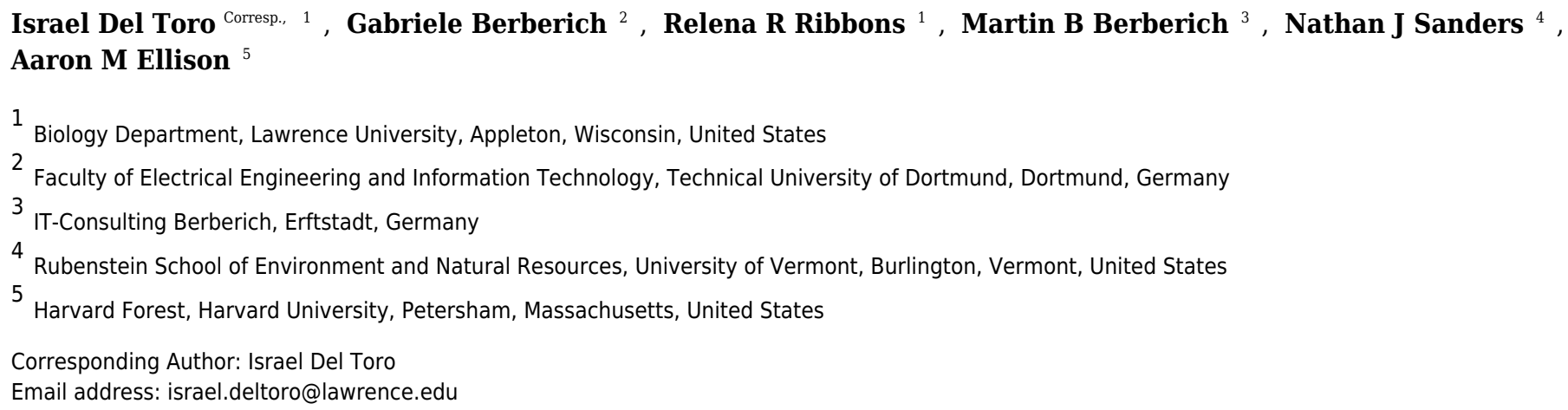

Ecological studies often are subjected to unintentional biases, suggesting that improved research designs for hypothesis testing should be used. Double-blind ecological studies are rare but necessary to minimize sampling biases and omission errors, and improve the reliability of research. We used a double-blind design to evaluate associations between nests of red wood ants (Formica rufa, RWA) and the distribution of tectonic faults. We randomly sampled two regions in western Denmark to map the spatial distribution of RWA nests. We then calculated nest proximity to the nearest active tectonic faults. Red wood ant nests were eight times more likely to be found within 60 meters of known tectonic faults than were random points in the same region but without nests. This pattern paralleled the directionality of the fault system, with NNE-SSW faults having the strongest associations with RWA nests. The nest locations were collected without knowledge of the spatial distribution of active faults thus we are confident that the results are neither biased nor artefactual. This example highlights the benefits of double-blind designs in reducing sampling biases, testing controversial hypotheses, and increasing the reliability of the conclusions of research. 
1 Nests of red wood ants (Formica rufa-group) are positively associated with tectonic faults: a

2 double-blind test

3

4 Authors: Israel Del Toro ${ }^{1,2}$, Gabriele M. Berberich ${ }^{3}$, Relena R. Ribbons ${ }^{1}$, Martin B. Berberich ${ }^{4}$,

5 Nathan J. Sanders ${ }^{2,5}$, Aaron M. Ellison 6

6

7 Institutions:

8 1Biology Department, Lawrence University, Appleton WI, USA

$9{ }^{2}$ Center for Macroecology, Evolution, and Climate, University of Copenhagen, Copenhagen,

10 Denmark

$11{ }^{3}$ Faculty of Electrical Engineering and Information Technology, Technical University of

12 Dortmund, Dortmund, Germany

$13{ }^{4}$ IT-Consulting Berberich, Erftstadt, Germany

$14{ }^{5}$ Rubenstein School of Environment and Natural Resources, University of Vermont, Burlington, 15 Vermont, USA

$16{ }^{6}$ Harvard University, Harvard Forest, Petersham, Massachusetts, USA

\section{Abstract}

19 Ecological studies often are subjected to unintentional biases, suggesting that improved research 20 designs for hypothesis testing should be used. Double-blind ecological studies are rare but 21 necessary to minimize sampling biases and omission errors, and improve the reliability of

22 research. We used a double-blind design to evaluate associations between nests of red wood ants 23 (Formica rufa, RWA) and the distribution of tectonic faults. We randomly sampled two regions 
24 in western Denmark to map the spatial distribution of RWA nests. We then calculated nest

25 proximity to the nearest active tectonic faults. Red wood ant nests were eight times more likely

26 to be found within 60 meters of known tectonic faults than were random points in the same

27 region but without nests. This pattern paralleled the directionality of the fault system, with NNE-

28 SSW faults having the strongest associations with RWA nests. The nest locations were collected

29 without knowledge of the spatial distribution of active faults thus we are confident that the

30 results are neither biased nor artefactual. This example highlights the benefits of double-blind

31 designs in reducing sampling biases, testing controversial hypotheses, and increasing the

32 reliability of the conclusions of research.

\section{Introduction}

35 A central question for ecology - the study of the distribution and abundance of organisms - is

36 why do organisms occur where they do? Explanations include relationships between organisms

37 and specific environments, interspecific interactions, or random chance. All of these explanations

38 have been suggested to apply to ants, one of the most widespread and abundant taxon on Earth

39 (Hölldobler \& Wilson, 1990; Lach, Parr \& Abbott, 2010). Berberich and Schreiber (2013) and

40 Berberich et al. (2016b) reported a seemingly peculiar positive spatial association between the

41 geographically widespread, conspicuous red wood ants (Formica rufa-group) and seismically

42 active, degassing tectonic faults. This work has been difficult to publish because reviewers have

43 suggested that the authors are ignoring alternative explanations or are ignorant of the basic

44 biology of ants. Such critiques are familiar to anyone who has proposed a new or controversial

45 hypothesis, but it is indeed peculiar that ants would be associated with degassing tectonic faults. 

study. Double-blind studies, in which treatment assignments (or data collected) are concealed to

researchers and subjects, are the most robust ones for testing any hypothesis, especially controversial ones, and increase the reliability of results and conclusions (Holman et al., 2015).

Double-blind designs are routine in medical sciences, but rare in ecology (Kardish et al., 2015).

To test more robustly the hypothesis that RWA nests are associated with active faults, we used a double-blind design in which myrmecologists who were unaware of this hypothesis or any published work on links between RWA and seismic activity (IDT and RRR) were sent into the field to map RWA nests. Simultaneously, maps of active tectonic faults in the region were obtained and organized by geoscientists (GMB and MBB) without any knowledge of the field data. With these two independently collected datasets, we then asked whether ants were positively associated with tectonic faults.

\section{Methods and Materials}

\section{Sampling design and data collection}

With no prior knowledge, IDT and RRR surveyed two regions of the Jutland Peninsula of Denmark: Thisted in the north and Klosterhede in the south (Fig 1A-C). Both study areas are located within the Permian-Cenozoic Danish Basin, which was formed by crustal extension, subsidence, and local faulting (Nielsen, 2003). This basin is bounded in the north by the seismically active, NW-SE striking fault system of the Sorgenfrei-Tornquist-Zone (STZ in Fig. 1A) and in the south by the basement blocks of the Ringkøbing-Fyn High and the Brande Graben (RFH and BG in Fig. 1A). The dominating compressional stress field is orientated 
69 primarily NW-SE direction (Fig. 1D) but scatters in different regions (Gregersen, 2002;

70 Helmholtz Centre Potsdam - GFZ German Research Centre for Geosciences, 2008).

71 The Thisted region $\left(\sim 670 \mathrm{~km}^{2}\right)$ included parts of the Thy National Park. The Klosterhede

72 region $\left(\sim 700 \mathrm{~km}^{2}\right)$, included the Klosterhede plantation, the third largest forested area in

73 Denmark. Landscapes and vegetation communities varied between the two sampling regions.

74 Coastal dunes dominated the Thisted region, whereas a mix of grasslands, pine and oak forests, 75 and conifer plantations dominated the Klosterhede region. Agricultural lands in both regions 76 were primarily rapeseed plantations.

77 Before surveying for RWA nests, and with no prior knowledge of the spatial distribution 78 of tectonic faults, the two regions were subdivided into $\sim 1000,1000 \times 1500$-m grid cells. One 79 hundred of the cells in each region were selected at random for mapping RWA nests, using the rnorm function in $\mathrm{R}$ (version 3.31). At each site, we used an adaptive sampling design to search

81 for RWA nests. If no RWA nests were encountered within an initial 30-minute sampling period, 82 we considered RWA to be absent from the grid cell. However, if a RWA nest was encountered 83 within an initial 30 minutes of searching, the survey was continued for an additional 30 minutes; 84 this process was repeated until no new nests were found within the survey grid cell boundaries.

85 The location of each RWA nest found was recorded using a Garmin Oregon 600 GPS unit 86 (Garmin Olathe, Kansas, USA); three individual worker ants were collected for subsequent 87 species identification. Voucher specimens were deposited in the Natural History Museum of 88 Denmark, Copenhagen.

89 GMB and MBB synthesized published data on geotectonic structures of the two study 90 areas (data in Supplementary Online Material) with tectonic maps provided by Stig Pedersen 91 (Geological Survey of Denmark) and the GEUS Map Server (The Geological Survey of 
92 Denmark and Greenland, 2015); they did so with no knowledge of the distributions of the RWA 93 nest data collected by IDT and RRR.

94

95 Spatial data and analyses

96 Spatial clustering of RWA nests was examined with Ripley's $K$ (Ripley, 1977). The distance

97 from each nest to the nearest fault line was calculated using the "distmap" function in the

98 “spstat” library (Baddeley, Rubak \& Turner, 2015) using R (version 3.3.1) (R Development Core

99 Team, 2014). We then estimated $\rho$ : the effect of the spatial covariate (i.e., distance to faults) on

100 the spatial intensity of the locations of the ant nests and the locations of cells without ants

101 (Baddeley et al., 2012). Finally, we used a Komlogrov-Smirnov (K-S) test to test if observed

102 RWA nests were closer to faults than locations sampled (i.e. the center of the sampled grid cell)

103 where no RWA nests were detected. We attempted to reduce sampling bias resulting from spatial

104 autocorrelation by using a random sampling grid. Remaining spatial autocorrelation or clustering 105 most likely is related to the polydomous and polygynous colony structure of many $F$. rufa-group 106 species (Seifert, 2007)

107

108 Results and Discussion

109

110

RWA nests occur closer to fault lines than expected by chance

111 RWA nests occurred in 28 of the 200 random grid cells (12 in the Thisted region and 16 in the

112 Klosterhede region). When RWA ants occurred in a sampled grid cell, there were generally $>1$

113 nest; in total we detected 273 nests of Formica species. All but four (one F. serviformica and

114 three $F$. fusca) were nests of Formica rufa-group ants: $86 \%$ were nests of $F$. polyctena and $12 \%$ 
115 were $F$. rufa. In both regions, RWA nests were spatially clustered according to Ripley's $K$, but 116 cells without ants were not spatially clustered (Fig. 1).

117 Covariance of RWA nests and faults was highest within $60 \mathrm{~m}$ of faults (Fig. 2A), and

118 approached zero at greater distances. In contrast, there was no observable covariance between

119 cells without RWA nests and their distance from faults (Fig. 2B). RWA nests were

120 approximately eight times more likely to be found at distances $<60 \mathrm{~m}$ from a fault than were cells 121 without ants $(K-S$ test $\mathrm{D}=0.373, P<0.001)$.

122 The directionality of a fault also affected the covariance between the spatial intensity of

123 RWA nests and their distance to faults (Fig. 2C-2H). Specifically, at distances $<100 \mathrm{~m}$ from an

124 active fault and relative to grid cells lacking ants, RWA nests were 10 times more likely along

125 faults trending NNE-SSW (Fig. 2F) and up to eight times more likely on faults trending NW-SE

126 or NNW-SSE (Fig. 2C, 2D). These directions are associated with the present-day main tectonic

127 stress field and its scattering directions (Helmholtz Centre Potsdam - GFZ German Research

128 Centre for Geosciences, 2008). In contrast, RWA ants were only 2-4 times more likely to faults

129 trending NE-SW or WNW-ESE (Fig. 2E, 2G), and did not occur adjacent to faults trending

130 ENE-WSW (Fig. 2H).

131 To address further whether polydomous colony structure of $F$. polyctena could have

132 skewed our results, we repeated the analysis for F. rufa alone. Similar to the overall pattern,

133 Formica rufa tended to be clustered within 30 meters from existing degassing faults (Fig 3A).

134 We also tested this pattern without considering individual nests but only the plots where RWA

135 was present; once again the pattern remained consistent and showed a peak in association with

136 faults at distance between 0 and 30 meters (Fig. 3B). This suite of evidence leads us to propose a

137 hypothesis that drives the observed biological pattern and should be tested in subsequent studies. 
138 Previous work has associated microhabitat availability to the spatial structure of ant colonies

139 (Scharf, Fischer-Blass \& Foitzik, 2011). In this study system, we argue that the underlying fault

140 lines may be providing a warmer thermal microhabitat, which drives the spatial clustering of

141 RWA colonies.

142 On the use of double-blind studies in ecology

143 The scientific method emphasizes accurate, unbiased, and objective experiments or observations.

144 Because research results can be biased by design or our underlying belief in the correctness of

145 our hypothesis (confirmation bias: (Nickerson, 1998)), repeatable results and reliable conclusions

146 require that investigators do as much as possible to minimize bias in all aspects of a research

147 project (e.g., Rosenthal \& Rosnow, 2007). Double-blind designs provide the gold-standard for

148 unbiased experiments (Holman et al., 2015).

149 In the interest of avoiding bias and increasing the repeatability and reliability of

150 ecological research, we suggest that the benefits of double-blind studies far outweigh the

151 additional costs and logistical complications of creating blinded research teams. The need for

152 multiple research teams leads directly to increased costs and additional project coordination.

153 Trade-offs among personnel, sampling effort, and sampling intensity depend on available

154 resources. In our study, for example, we reduced sampling effort by randomly, not exhaustively,

155 sampling the $\sim 1400 \mathrm{~km}^{2}$ of the pre-defined study regions. A second cost of a double-blind study

156 such as ones focused on species occurrences is the general tendency to focus on where a species

157 occurs, as opposed to where it does not. For example, most species distribution models are based

158 only on "presence-only" data, as absences are rarely recorded (Berberich et al., 2016a).Yet as we

159 have shown here, the samples of locations lacking RWA nests were crucial for determining

160 whether RWA nests and fault systems had meaningful patterns of covariance. 
162 importance cannot be overestimated. Results and conclusions of double-blind studies are

163 unlikely to be biased by the views and perspectives of the researchers themselves. Investment in

164 appropriately replicated double-blind studies also may be more cost-effective because they rarely

165 need to be repeated, even if the results are unexpected. Just as double-blind studies in medicine

166 have led to reliable treatments that for injury and disease, double-blind studies in ecology will

167 provide us with high-quality unbiased data of how the natural world is structured and is

168 changing.

\section{References}

170 Baddeley a., Chang YM., Y. S., Turner R. 2012. Nonparametric estimation of the dependence of 171 a spatial point process on spatial covariates. Statistics and Its Interface 5:221-236. DOI:

$172 \quad$ 10.4310/SII.2012.v5.n2.a7.

173 Baddeley A., Rubak E., Turner R. 2015. Spatial Point Patterns: Methodology and Applications 174 with R.

175 Berberich GM., Dormann CF., Klimetzek D., Berberich MB., Sanders NJ., Ellison AM. $2016 a$.

176 Detection probabilities for sessile organisms. Ecosphere 7:e01546. DOI:

$177 \quad 10.1002 /$ ecs2.1546.

178 Berberich G., Grumpe A., Berberich M., Klimetzek D., Wöhler C. 2016b. Are red wood ants 179 (Formica rufa-group) tectonic indicators? A statistical approach. Ecological Indicators $180 \quad$ 61:968-979. DOI: 10.1016/j.ecolind.2015.10.055.

181 Berberich G., Schreiber U. 2013. GeoBioScience: Red wood ants as bioindicators for active 182 tectonic fault systems in the West Eifel (Germany). Animals 3:475-498. DOI:

$183 \quad$ 10.3390/ani3020475. 
184 Gregersen Sø. 2002. Earthquakes and change of stress since the ice age inScandinavia. Bulletin 185 of the Gological Soceity of Denmark 49:73-78.

186 Helmholtz Centre Potsdam - GFZ German Research Centre for Geosciences. 2008.The World

187 Stress Map Project - A Service for Earth System Management

188 Hölldobler B., Wilson EO. 1990. The Ants.

189 Holman L., Head ML., Lanfear R., Jennions MD. 2015. Evidence of experimental bias in the life 190 sciences: Why we need blind data recording. PLoS Biology 13. DOI:

$191 \quad$ 10.1371/journal.pbio.1002190.

192 Kardish MR., Mueller UG., Amador-Vargas S., Dietrich EI., Ma R., Barrett B., Fang C-C. 2015.

193 Blind trust in unblinded observation in Ecology, Evolution, and Behavior. Frontiers in

$194 \quad$ Ecology and Evolution 3:1-4. DOI: 10.3389/fevo.2015.00051.

195 Lach L., Parr C., Abbott K. 2010. Ant Ecology. Oxford: Oxford University Press.

196 Nickerson RS. 1998. Confirmation bias: A ubiquitous phenomenon in many guises. Review of 197 General Psychology 2:175-220. DOI: 10.1037/1089-2680.2.2.175.

198 Nielsen LH. 2003. The Jurassic of Denmark and Greenland: Late Triassic - Jurassic 199 development of the Danish Basin and the Fennoscandian Border Zone, southern 200 Scandinavia. Geological Survey of Denmark and Greenland Bulletin 1:459-526.

201 R Development Core Team R. 2014. R: A Language and Environment for Statistical Computing. 202 R Foundation for Statistical Computing 1:409. DOI: 10.1007/978-3-540-74686-7.

203 Ripley BD. 1977. Modelling spatial patterns. Journal of the Royal Statistical Society. Series B 204 (Methodological) 39:172-212. DOI: 10.1046/j.1369-7412.2003.05285.x.

205 Rosenthal R., Rosnow R. 2007. Essentials of Behavioral Research: Methods and Data Analysis. $206 \quad$ New York: McGraw-Hill. 
207 Scharf I., Fischer-Blass B., Foitzik S. 2011. Spatial structure and nest demography reveal the 208 influence of competition, parasitism and habitat quality on slavemaking ants and their hosts. 209 BMC ecology 11:9. DOI: 10.1186/1472-6785-11-9.

210 Seifert B. 2007. Die Ameisen Mittel- und Nordeuropas. Boxberg: Lutra Verlags- und 211 Vertriebsgesellschaft.

212 The Geological Survey of Denmark and Greenland. 2015.GEUS Server: Geologisk Kort over the 213 Danske Undergrund.

214 


\section{Figure 1}

Figure 1:

A) Map of Jutland Peninsula, highlighting the two sampling regions and major tectonic units .

Thisted (Figure 1B) and Klosterhede Regions (Figure 1C) are shown in detail. Thisted region (North) and the Klosterhede region (South) are shaded in red. Blue points indicate absence of RWA from grid survey; red points indicate the location of RWA nests. D) Distribution of faults in the Jutland Peninsula (after Veijbeck, 1997; Petersen et al. 2008; Pedersen \& Gravesen 2010 and GEUS Server, 2015) with red and blue points as in C and D.
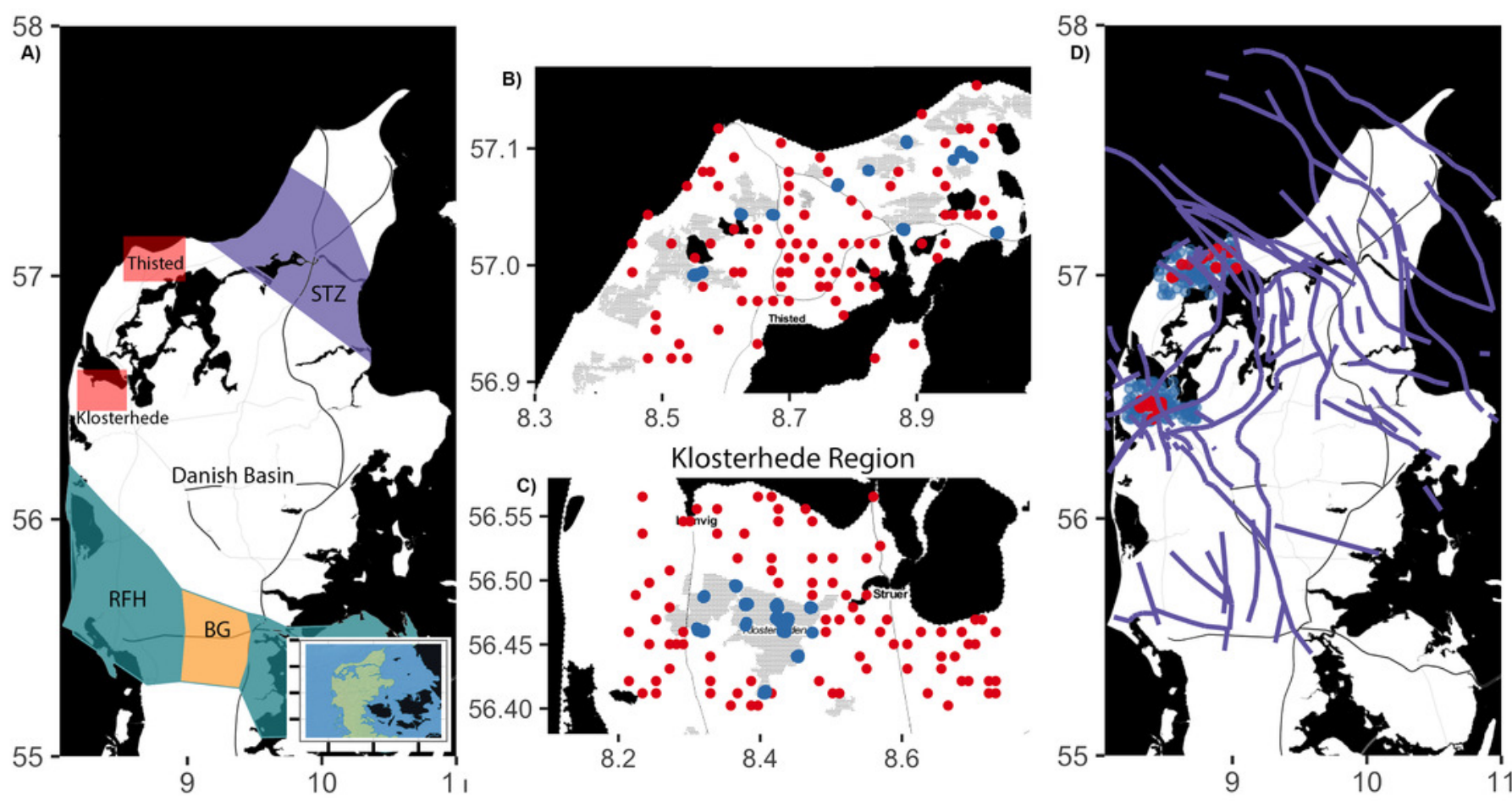
Figure 2

Figure 2:

A) Correlation of ant distributions with tectonic fault zones in the region. B) Correlation of ant absences with tectonic fault zones in the region. $\mathrm{C}-\mathrm{H}$ ) Correlations of ant distributions with direction patterns of tectonic fault zones in the pooled dataset.
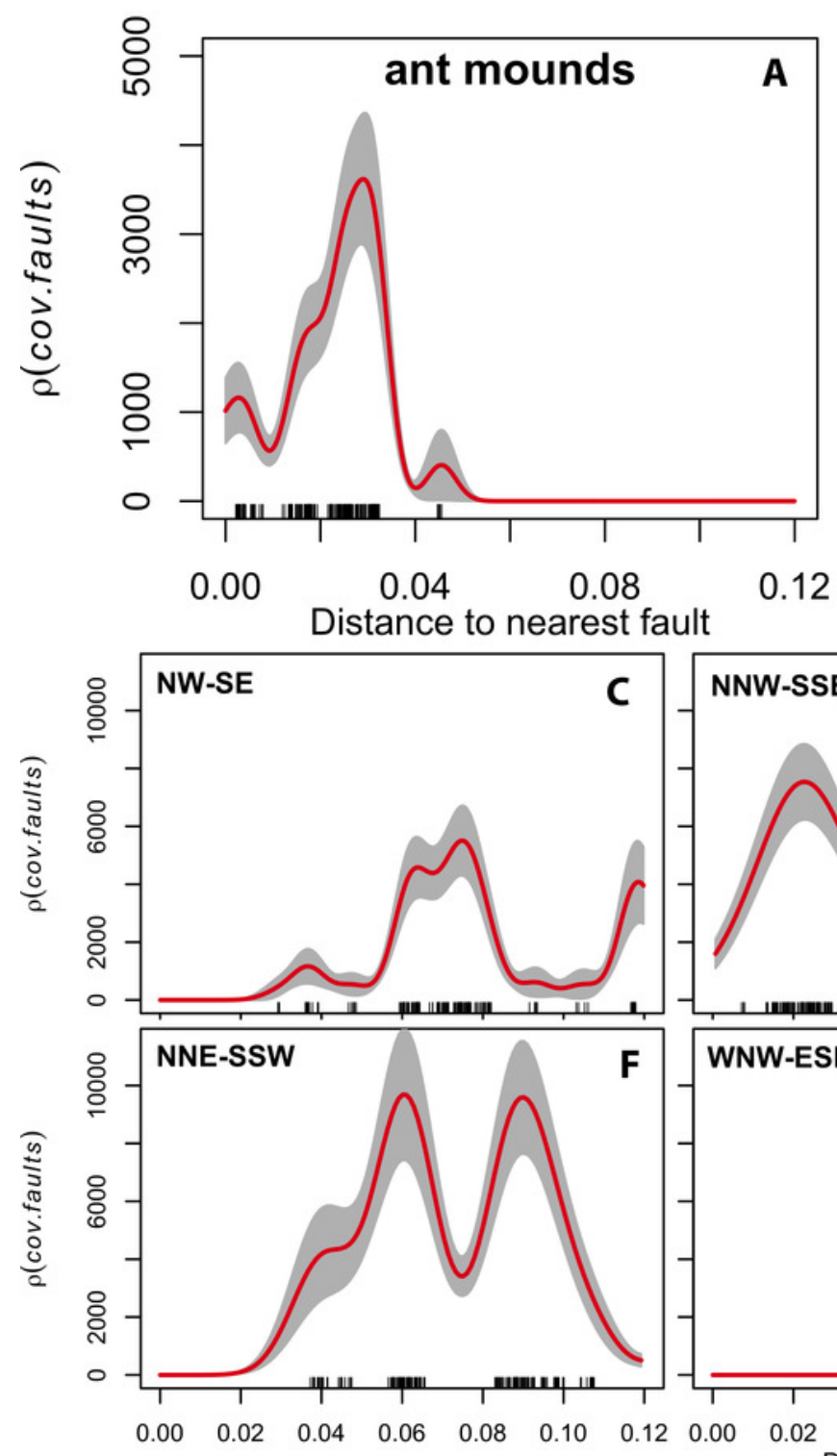
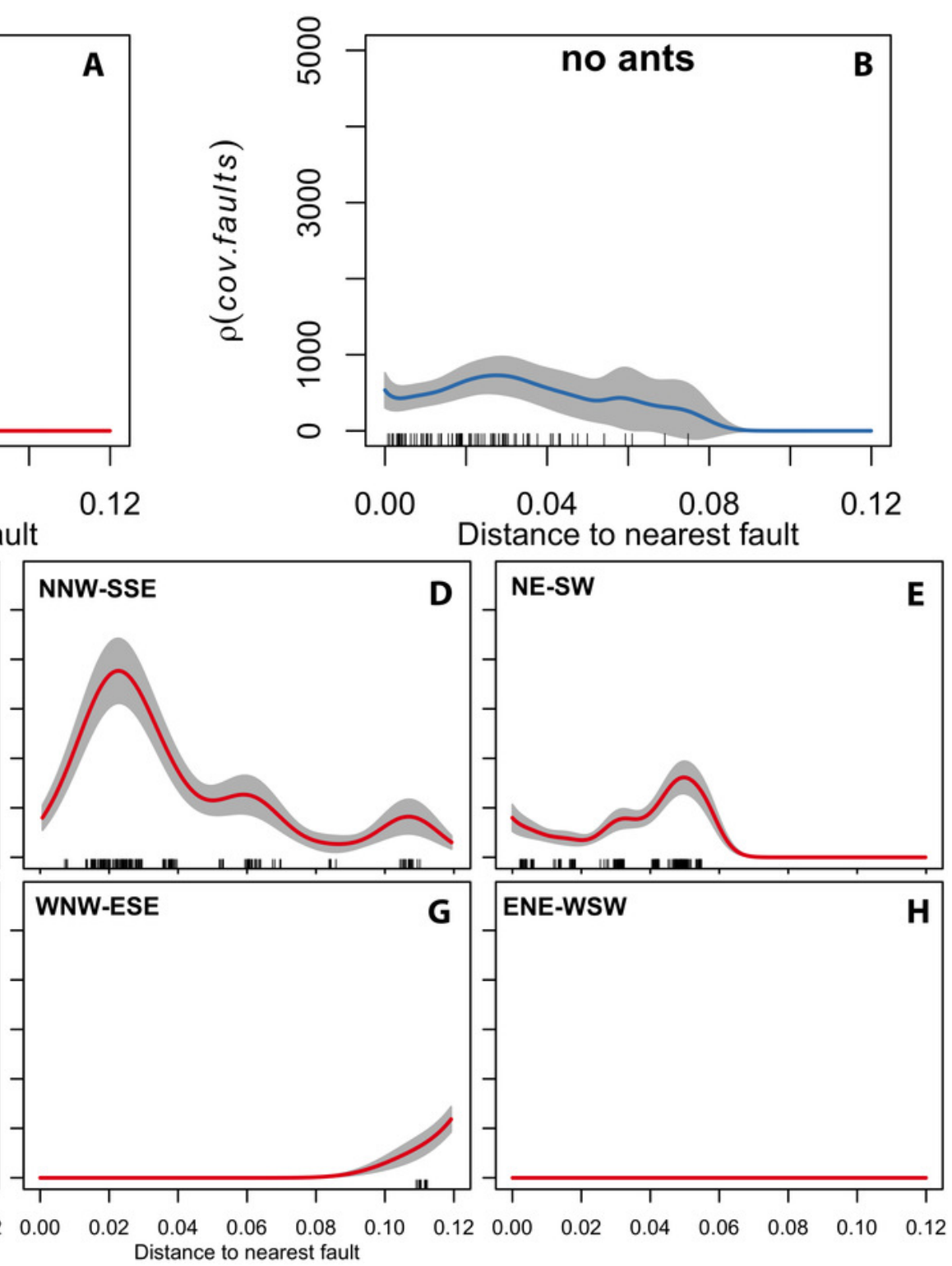
Figure 3

Figure 3:

A) Spatial correlation of Formica rufa with tectonic faults B) Spatial Correlation of grid units with RWA with tectonic faults.

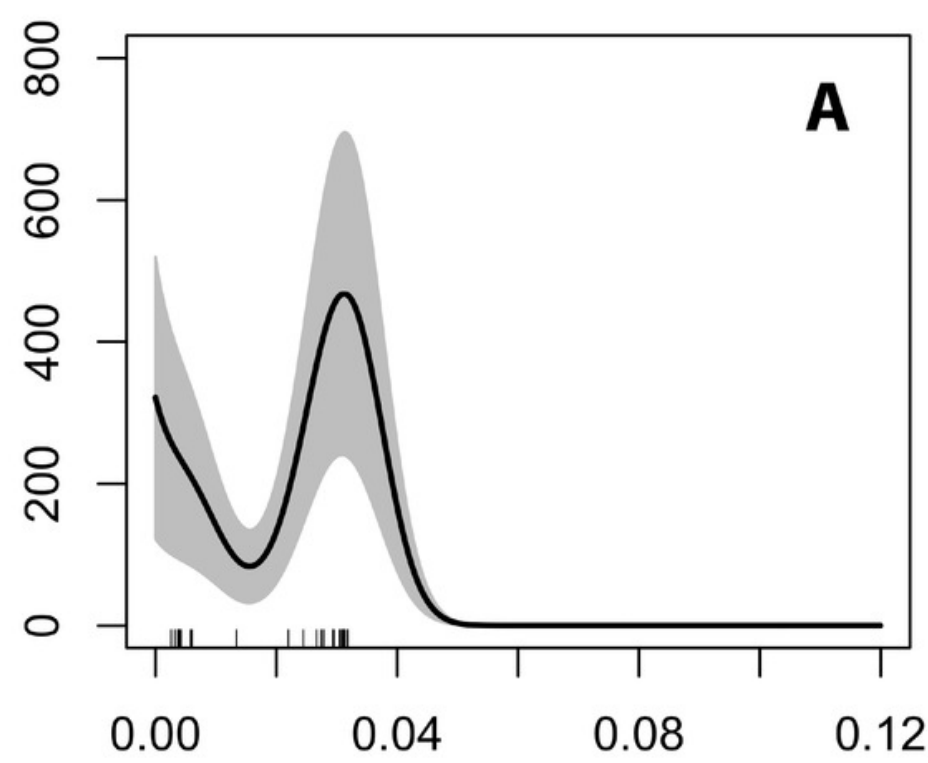

Distance to nearest fault

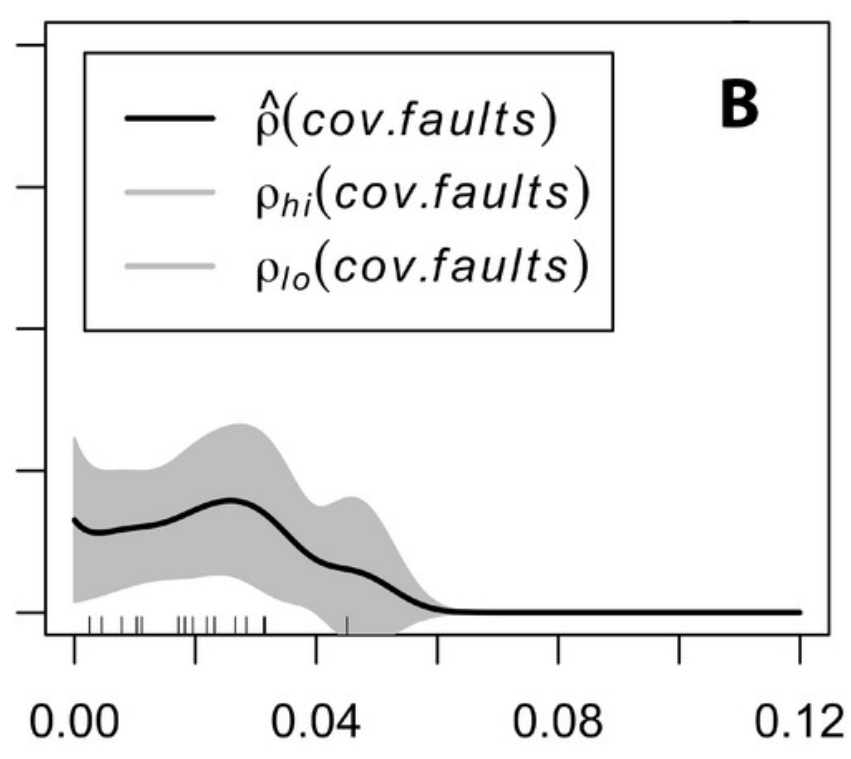

Distance to nearest fault 